\title{
INVOLVEMENT OF THE VANILLOID RECEPTOR 1 IN THE MECHANISM OF ANALGETIC EFFECT OF KETOROLAC
}

Abstract The existing ideas about the ketorolac mechanism of analgetic potency are associated with its effect on COX isoenzymes and its significant potency needs to be explained more completely. Its impact on vanilloid receptors 1 (TRPV1) can also be an effective mechanism of analgetic action. We have evaluated the analgetic potential of ketorolac on the basis of its influence on TRPV1. It is known that Tyr511 and Ser512 amino acids are active central components of TRPV1. Thereby the synthesis of the dipeptide Tyr-Ser has been conducted as a model of the TRPV1 active centre. In our model test, using spectrofluorometry, the formation of intermolecular complexes was shown: "ketorolac - Tyr-Ser" and "capsaicin - Tyr-Ser" at stability constants $\mathrm{Kr}=0.53 \cdot 10^{-4} \mathrm{~L} / \mathrm{mol}$; $\mathrm{K}_{\mathrm{kor}}=0.998$ and $\mathrm{K}_{\mathrm{r}}=0.3 \cdot 10^{-4} \mathrm{~L} / \mathrm{mol} \mathrm{K}_{\mathrm{kor}}=0.998$, respectively. Verification of the data was proved in experiments in vitro (the preparation of portal vein) and in vivo (Tail-flick model), with the TRPV1 agonist and antagonist. On portal vein, it was established (from initial level) by Krebs solution that the range of relaxation of smooth muscles of the portal vein (SM) was as follows at the concentration of capsaicin $0.1 \mu \mathrm{mol} / \mathrm{L}+30.3 \% \pm 5.3 \%$, capsazepine $0.5 \mu \mathrm{mol} / \mathrm{L}-3.2 \pm 2.7 \%$ and ketorolac $1.0 \mu \mathrm{mol} / \mathrm{L}-60.0 \pm 7.0 \%$. In the experiment, at the above mentioned doses of ketorolac on the background of the action of the capsaicin (capsazepine), the range of relaxation of smooth muscles $(\mathrm{SM})$ of the portal vein was $-59.3 \pm 5.0 \%$ and $-63.0 \pm 6.0 \%$ respectively testifying to the fact that the effect of capsaicinoids was neutralised by ketorolac. On the Tail-flick model, an atypical potentiation of the ketorolac antinociception at simultaneous use with the capsaicin was shown. The obtained data allow suggesting that TRPV1 can activate the ketorolac antinociceptive effects.

\section{Introduction}

During the recent decades, due to a discovery in numbers of different types of the specific receptors which are located on nociceptive neurons (tetrodotoxin-resistant sodium channel, purinergic receptor $\mathrm{RH} 3$, vanilloid receptor 1 (TRPV1), etc.), special attention was given to the receptor action both at the creation of the new analgesics and at the study of the pharmacodynamics of already known analgesics. Today, general notions of mechanisms of actions of non-narcotic analgesics and non-steroidal anti-inflammatory drugs do not completely explain their pharmacological properties, including the analgesic effect. Thus, scientific data on the pharmacodynamics of paracetamol, amizonum, ketoprofen, diclofenac, ibuprofen and so on are debatable (Aronoff et al., 2006; Díaz-Reval et al., 2004; Hugestgtt et al., 2005; Masubuchi et al., 2002; Roberts and Marrow, 2001). As result of the researches, the new mechanisms of actions of the analgesic drugs correcting substantially the pharmacodynamics data have been detected. These drugs are widely known and used in clinic. Therefore, for instance, the ability of diclofenac to block the potential- dependent sodium channels, acid-dependent ion channels (ASICs) as well as the positive allosteric modulation of KCNQ and BK sodium channels has been revealed (Roberts and Marrow, 2001). We also demonstrated the potential analgetic effect of indometacin, including its influence on calcium channels. Therein the data of significant analgetic potential of ketorolac fit into cyclooxygenase theory insufficiently (Varrassi et al., 1999). Therefore, we investigated the effect of ketorolac on TRPV1 as well as the effect of activation or inhibition of vanilloid system on the antinociceptive activity of the analgesic.

\section{Materials and Methods}

\section{Animals}

For the experiment, male Wistar rats (150-200 g) were used (animals breeding from vivarium of the SE "Institute of pharmacology and toxicology AMS of Ukraine", Kiev, Ukraine). Throughout the experiment, the animals were randomised in 
groups of five in cages with the bedding composed of wood shavings (exchanged daily). The animals had free access to a standard commercial diet and water. The animals were kept under a stable regimen of $12 \mathrm{~h}$ light/12 $\mathrm{h}$ darkness. All studies were performed in accordance with the requirements of the State Expert Center of the Ministry of Health of Ukraine and the rules of the "European Convention for the Protection of Vertebrate Animals used for Experimental and Other Scientific Purpose" (Strasbourg city, 1986). Animals were sacrificed by decapitation under ether anaesthesia.

\section{Drugs and analysers}

The ketorolac substance (JSC "Lec-Chem" Ukraine), TRPV1 agonist capsaicin (Sigma-Aldrich, USA), TRPV1 antagonist capsazepine (Sigma-Aldrich, USA) and dipeptide Tyr-Ser (TyrSer) synthesised in the Department of Synthesis of Biologically Active Substances of the SE "Institute of pharmacology and toxicology AMS of Ukraine" (Fig. 1) were used in the study.<smiles>NC(CO)C(=O)NC(Cc1ccc(O)cc1)C(=O)O</smiles>

Fig. 1. Structural formula of dipeptide Tyr-Ser.

\section{Research methods}

Complex formation of ketorolac and capsaicin with one of the TRPV1 active centres, dipeptide Tyr-Ser, was studied using Benesi-Hildebrand method (Akerman et al., 2004). The electronic absorption spectra of capsaicin and ketorolac solutions in ethanol were recorded using spectrofluorometry. For this research, we prepared the solutions with a constant concentration of these investigated substances: capsaicin $1 \cdot 10^{-4} \mathrm{~mol} / \mathrm{L}$, ketorolac $2.5 \cdot 10^{-5} \mathrm{~mol} / \mathrm{L}$ and the ratio of substances with Tyr-Ser between 1:2 and 1:32. Stability constant $\left(\mathrm{K}_{\mathrm{r}}\right)$ was determined under the chart $1 / \Delta \mathrm{D}-1 / \mathrm{C}_{\mathrm{Tyr}-\mathrm{Ser}}$ by the point of intersection with the abscissa axis. Correlation coefficient Kkor was calculated. We used the following features: $C_{B}$ - concentration of alcohol solution TYR-SER corresponding to its concentration in the mixture to determine complex formation; $C_{A}: C_{B}$ - concentration ratios of $A$ and $B$ substances in the mixture to determine complex formation; $D_{\text {kompl }}$ - optical density of the mixture to determine complex formation; $D_{A}, D_{B}$ - optical density of the substance corresponding to its concentration in the mixture to determine complex formation of $A$ and $B$, respectively; $D_{\Sigma(A+B)}$ - the sum of optical densities of $A$ and $B$ substances in concentrations corresponding to their concentrations in the mixture; $\Delta D=D_{\text {kompl }}-D_{\Sigma(A+B)}$. In our experiment, the assessment of the ketorolac effect on TRPV1 in in vitro studies was carried out with use of portal vein preparations of $4-6 \mathrm{~mm}$ in length and $2-3.5 \mathrm{mg}$ of weight, which was isolated from adult rats. The veins preparations were perfused by Krebs solution of the following composition (mmol/L): $\mathrm{NaCl} 133 ; \mathrm{KCl} 4.7 ; \mathrm{NaHCO}_{3}$ 16.3; $\mathrm{NaHPO}_{4}$ 1.38; $\mathrm{CaCl}_{2} 2.5 ; \mathrm{MgCl}_{2} 1.2 ;$ glucose $7.8 ; 7.4 \mathrm{pH}$ and temperature of $37^{\circ} \mathrm{C}$. EC50 of analgesics was used in a dose of $1 \mu \mathrm{mol} / \mathrm{L}$. The EC50 of substances affecting TRPV1 was used in doses of $0.1 \mu \mathrm{mol} / \mathrm{L}$ and $0.5 \mu \mathrm{mol} / \mathrm{L}$ for capsaicin and capsazepine, respectively 1 (Akerman et al., 2004), 10 (Pegram, 1980). We reg istered the isometric contractions of the portal vein through the strain gauge transducer attached to the amplifier and signal filter/amplifier. The analogue signal was converted to digital by using the LabTrax device (WPI, Inc). We registered and recorded the digital data in the DataTrax2 program (WPI, Inc). Static data were processed by using wavelet analysis (The engineer's ultimate guide to wavelet analysis, 2011).

The data verification in vitro was carried out on the in vivo Tail-flick model 6 (Komlos, 1980). We evaluated the rats in groups of five. The test substances were administered in doses $\mathrm{ED}_{50}$ : capsaicin $10 \mathrm{mg} / \mathrm{kg}$ s.c., capsazepine $1 \mathrm{mg} / \mathrm{kg}$ i.p. and ketorolac $3 \mathrm{mg} / \mathrm{kg}$ i.m. The Tail-flick latency was evaluated by the analgesiometer (Ugo Baile, Italy). The strength of the current passing through the naked nicrome wire was kept constant at 6 Amps. The distance between the heat source and the tail skin was $1.5 \mathrm{~cm}$. The site of application of the radiant heat in the tail was maintained at $2.5 \mathrm{~cm}$, measured from the root of the tail. The cut-off reaction time was fixed at $15 \mathrm{sec}$ to avoid tissue damage. The experiment was conducted according to the scheme: 1 ) Injection of the agonist/antagonist followed by injection of the analgesic ( 5 min later). Measurements were made 15, 30 and 60 min after the injection of the agonist/antagonist. 2) Injection of the analgesic followed by injection of the agonist/antagonist (5 min later). After the injection of ketorolac, measurements were made at 15, 30 and $60 \mathrm{~min}$. Static handling of data was performed using nonparametric statistical method (Gibbons and Chakraborti, 2011). Data are reported as mean \pm SD. A level of $P<0.05$ was accepted as statistically significant.

\section{Results}

Interaction of the capsaicin molecule with dipeptide Tyr-Ser is characterised by an intermolecular complex formation at the level $\mathrm{K}_{\mathrm{r}}=0.3 \cdot 10^{-4} \mathrm{~L} / \mathrm{mol}$ (Fig. 1, Table 1). Determination by spectrofluorimetry of ketorolac complex formation with dipeptide Tyr-Ser in ethanol at the wavelength of $312 \mathrm{~nm}$ showed that there is a complex formation, where the conditional constant for the complex formation is $\mathrm{K}_{\mathrm{r}}=0.53 \cdot 10^{-4} \mathrm{~L} / \mathrm{mol}$ (Fig. 3, Table 2). In addition, $\lambda_{\max }$ of ketorolac (in ethanol solution) of $323 \mathrm{~nm}$ in its complex shifted 
to $315 \mathrm{~nm}$ (in $18 \mathrm{~nm}$ to shortwave part - hypochromic shift). Tables 3 and 4 represent the obtained data of changes in amplitude and frequency of portal vein contractions under the effect both of the TRPV 1 agonist and antagonist, as well as under the effect of ketorolac with mono use and on the backdrop of the TRPV1 activator capsaicin and the TRPV1 antagonist capsazepine. It is shown that the TRPV1 agonist capsaicin and antagonist capsazepine in concentrations of $0.1 \mu \mathrm{mol} / \mathrm{L}$ influence the amplitude and frequency of portal vein contractions which demonstrate the presence of TRPV1 in its tissues. At the same time, the frequency of portal vein contractions under the effect of the capsaicin was reduced by $11.1 \%-13.2 \%$ and under the effect of capsazepine was increased by $2.0 \%-4.2 \%$. The capsazepine action increased the amplitude of portal vein contraction by $30.3 \%$. The capsaicin influences the portal vein wall smooth muscles contraction which displayed both the amplitude and frequency contractions values. Ketorolac significantly reduced the frequency of contractions of the portal vein while reducing the amplitude of contractions. The use of ketorolac in combination with capsaicin and capsazepine could neutralise its effect.

In our study on the Tail-flick model, it was revealed that the introduction of ketorolac caused a significant analgetic effect, the peak of which we observed 30 min after its introduction (Table 5). The studies showed that introduction of ketorolac first to the animals followed by the introduction of capsaicin caused a significant increase of latency, the peak of which was achieved in $30 \mathrm{~min}(+138.7 \%)$ after the beginning of the study. The introduction of capsaicin before ketorolac also caused a significant increase of the effect though at a low level (89.3\%). The complex administration of capsazepine and ketorolac (as shown in the chart with capsazepine + ketorolac and in the chart with ketorolac + capsazepine) did not cause any fundamental changes as compared with ketorolac alone. We now discuss the influence of capsaicin on antinociceptive effects of ketorolac and the factual absence of modulation of analgetic effects of capsazepine.

\section{Discussion}

The structure of capsaicinoids is divided into three segments: A (4-hydroxy-replaced benzene ring), B (amide or ether fragment) and $C$ (aliphatic fragment). It is known that the A segment of capsaicinoids provides the activity up to $75 \%$ and any modifications in it lead to significant changes in the agonist properties. Capsaicinoids without the B segment are characterised by smaller affinity to TRPV 1 and the absence of $C$ segment reduces activity (Roberts and Marrow, 2001). For a ketorolac molecule, segments B and C are absent. However, the ketorolac molecular structure includes a carboxyl group, which can theoretically have an effect on the conformational structural changes of TRPV1 because of the polarisation of the side chains radicals of the Ser, Thr, Arg, Lys, His amino acids and depolarisation of the Asp and Glu radicals under the influence of $\mathrm{pH}$ changes in the TRPV1 intercellular space and other factors (Scotland et al., 2004). On this basis, we carried

Table 1. Spectrofluorimetric determination of complex formation of capsaicin (A) with Tyr-Ser (B) in ethanol (concentration of capsaicin is constant $C_{A}=1 \cdot 10^{-4} \mathrm{~mol} / \mathrm{L}, \pi=278 \mathrm{~nm}, D \lambda_{A}=0.263$ ).

\begin{tabular}{|c|c|c|c|c|c|c|c|c|c|c|}
\hline $\begin{array}{c}\mathrm{C}_{\mathrm{B}} \cdot 10^{-4} \\
\mathrm{~mol} / \mathrm{L}\end{array}$ & $\mathrm{C}_{\mathrm{A}}: \mathrm{C}_{\mathrm{B}}$ & $\begin{array}{c}\left(1 / \mathrm{C}_{\mathrm{B}}\right) \cdot 10^{-4} \\
\mathrm{~mol} / \mathrm{L}\end{array}$ & $\mathrm{D}_{\mathrm{kompl}}$ & $\mathrm{D}_{\mathrm{A}}$ & $\mathrm{D}_{\mathrm{B}}$ & $\mathrm{D}_{\mathrm{y}(\mathrm{A}+\mathrm{B})}$ & $\Delta \mathrm{D}$ & $1 / \Delta \mathrm{D}$ \\
\hline 1 & $1: 2$ & 0.500 & 0.440 & 0.263 & 0.190 & 0.453 & -0.013 & -76.92 \\
\hline 2 & $1: 3$ & 0.300 & 0.529 & 0.263 & 0.283 & 0.546 & -0.017 & -58.82 \\
\hline 3 & $1: 5$ & 0.200 & 0.715 & 0.263 & 0.472 & 0.735 & -0.020 & -50.00 \\
\hline 4 & $1: 6$ & 0.166 & 0.812 & 0.263 & 0.570 & 0.833 & -0.021 & -47.60 \\
\hline 5 & $1: 7$ & 0.142 & 0.910 & 0.263 & 0.675 & 0.938 & -0.028 & -35.71 \\
\hline
\end{tabular}

Table 2. Spectrofluorimetric determination of complex formation of ketorolac $(A)$ with Tyr-Ser $(B)$ in ethanol (concentration of ketorolac is constant $C_{A}=2.5 \cdot 10^{-5} \mathrm{~mol} / \mathrm{L}, \pi=300 \mathrm{~nm}, D \lambda_{A}=0.220$ ).

\begin{tabular}{|c|c|c|c|c|c|c|c|c|c|}
\hline $\begin{array}{c}\mathrm{C}_{\mathrm{B}} \cdot 10-4 \\
\mathrm{~mol} / \mathrm{L}\end{array}$ & $\mathrm{C}_{\mathrm{A}}: \mathrm{C}_{\mathrm{B}}$ & $\begin{array}{c}\left(1 / \mathrm{C}_{\mathrm{B}}\right) \cdot 10^{-4} \\
\mathrm{~mol} / \mathrm{L}\end{array}$ & $\mathrm{D}_{\text {kompl }}$ & $\mathrm{D}_{\mathrm{A}}$ & $\mathrm{D}_{B}$ & $\mathrm{D}_{\mathrm{y}(\mathrm{A}+\mathrm{B})}$ & $\Delta \mathrm{D}$ & $1 / \Delta \mathrm{D}$ \\
\hline 1 & $1: 4$ & 1.000 & 0.260 & 0.220 & 0.0040 & 0.2240 & 0.0360 & 27.777 \\
\hline 2 & $1: 8$ & 0.500 & 0.286 & 0.220 & 0.0092 & 0.2292 & 0.0568 & 17.606 \\
\hline 3 & $1: 12$ & 0.333 & 0.300 & 0.220 & 0.0136 & 0.2336 & 0.0664 & 15.060 \\
\hline 4 & $1: 16$ & 0.250 & 0.312 & 0.220 & 0.0200 & 0.2400 & 0.0720 & 13.889 \\
\hline 5 & $1: 20$ & 0.200 & 0.324 & 0.220 & 0.0248 & 0.2448 & 0.0792 & 12.696 \\
\hline 7 & $1: 24$ & 0.166 & 0.328 & 0.220 & 0.320 & 0.2520 & 0.0770 & 13.158 \\
\hline 8 & $1: 28$ & 0.142 & 0.338 & 0.220 & 0.0360 & 0.2560 & 0.0820 & 12.195 \\
\hline
\end{tabular}


Table 3. Effect on ketorolac, capsaicin and capsazepine on the spontaneous activity of the portal vein. The data are in percentages to normal (in Krebs).

\begin{tabular}{|l|l|l}
\hline Group & Amplitude & Frequency \\
\hline Ketorolac, $\mathrm{n}=6$ & $-60.0 \pm 7 \%$ & $-5.86 \pm 1.9$ \\
\hline Capsaicin, $\mathrm{n}=16$ & $+30.3 \pm 5.3 \%$ & $-11.74 \pm 3.7$ \\
\hline Capsazepine, $\mathrm{n}=8$ & $-3.2 \pm 2.7 \%$ & $+6.92 \pm 1.9$
\end{tabular}

The reliability of all research $-95 \%$.

Table 4. Effect on ketorolac against capsaicin and applique capsazepine spontaneous activity on the portal vein. Percentage changes to the data activity of capsaicin/capsazepine.

\begin{tabular}{l|l|l|}
\hline Group & Amplitude & Frequency \\
\hline $\begin{array}{l}\text { Capsaicin } \\
\text { ketorolac, } \mathrm{n}=6\end{array}$ & $-59.3 \pm 5.0 \%$ & $-3.1 \pm 1.7$ \\
\hline $\begin{array}{l}\text { Capsazepine } \\
\text { ketorolac, } \mathrm{n}=6\end{array}$ & $-63.0 \pm 6.0 \%$ & $-3.5 \pm 1.80$ \\
\hline
\end{tabular}

The reliability of all research $-95 \%$.

out the research for the interaction of ketorolac with one of active centres of the TRPV1 dipeptide Tyr-Ser. In the model experiment of the estimation of bounding, the resistance constant $(\mathrm{Kr})$ "dipeptide Tyr-Ser - ketorolac" exceeded that of the complex "dipeptide Tyr-Ser - capsaicin". Taking into account that ketorolac is an active substance of ketorolac, but not a product of its metabolism, the interaction of analgesics with TRPV1 is theoretically possible (Mroszczak et al., 1987). We carried out further verification of the obtained data on the portal vein in vitro in a model experiment. Recently, TRPV1 receptors have been found in the vascular wall of mammals and their physiological role on the body was revealed; as well, vasoactive peptides influencing through the receptor on the vascular wall was detected (Scotland et al., 2004; Urban and Dray, 1991).
It was shown that they modulated cardiovascular system functions in a complex manner. Thus, capsaicin- and capsaicineinduced peptides could cause a vasodilatation, increasing the cardiac blood flow and facilitating the recovery after ischaemia (Scotland et al., 2004). On the other hand, there are the facts that the product of arachidonic acid metabolism, 20-hydroxyethanesulfonic acid, causes vasoconstriction by influence on TRPV1 (Premkumar, et al., 2008). Taking into account these factors, we can talk about the specific reactions for cardiovascular system caused by the action of these agents. We determined that capsaicin and capsazepine revealed a specific effect on portal vein contraction. Ketorolac has a powerful effect on the portal vein contraction (both on the amplitude and frequency). The introduction of this analgesic in combinations

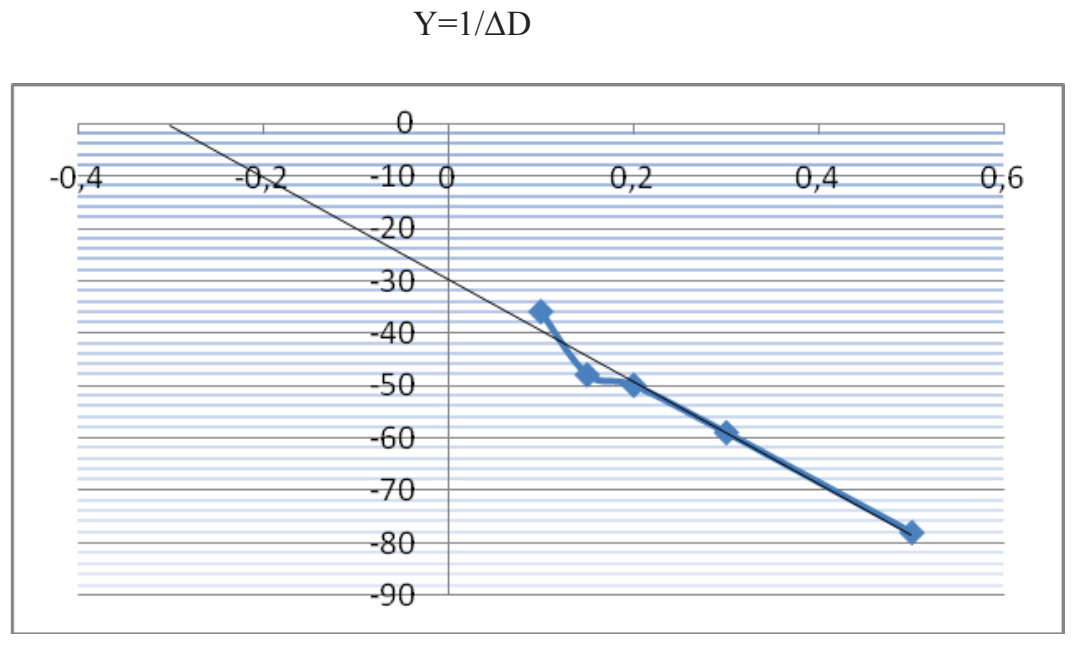

$$
\mathrm{X}=\left(1 / \mathrm{C}_{\mathrm{A}}\right) * 10^{4}, \mathrm{~L} / \mathrm{mol}
$$

Fig. 2. Spectrofluorimetric definition of capsaicin complex $(A)$ with Tyr-Ser (B) in ethanol. (Concentration of capsaicin is constant $\left.C_{A}=1 \cdot 10^{-4}, \mathrm{~mol} / \mathrm{L}, \lambda=278 \mathrm{~nm}, D \lambda_{A}=0.263\right)$ dependence of $1 / \Delta D-1 / \mathrm{S}_{B} \cdot \mathrm{Kr}=0,3 \cdot 10^{-4} \mathrm{~L} / \mathrm{mol}(\mathrm{Kkor}=-0.998)$ 
Table 5. Antinociceptive activity of ketorolac on the background of capsaicin/capsazepine on the Tail-flick model, $n=5$.

\begin{tabular}{|c|c|c|c|c|c|}
\hline Substance & \multirow{2}{*}{$\begin{array}{l}\text { Statistics of } \\
\text { indexes }\end{array}$} & Initial & $15 \mathrm{~min}$ & $30 \mathrm{~min}$ & $60 \mathrm{~min}$ \\
\hline Group & & \multicolumn{4}{|c|}{ The latent period of the reaction (s) } \\
\hline \multirow[t]{2}{*}{ Ketorolac } & M & 3.4 & 4.4 & 5.0 & 3.8 \\
\hline & $\pm \mathrm{m}$ & 0.4 & 0.8 & 0.7 & 0.5 \\
\hline $\begin{array}{l}\text { Changes to the initial point, } \\
\%\end{array}$ & - & - & $+27.9^{*}$ & $+46.5^{*}$ & +10.4 \\
\hline \multirow[t]{2}{*}{ Capsaicin } & M & 3.2 & 2.7 & 2.7 & 3.2 \\
\hline & $\pm \mathrm{m}$ & 0.9 & 0.4 & 1.4 & 0.8 \\
\hline $\begin{array}{l}\text { Changes to the initial point, } \\
\%\end{array}$ & - & - & -16.6 & $-14.1^{*}$ & -0.6 \\
\hline \multirow[t]{2}{*}{ Ketorolac + capsaicin } & M & 3.8 & 6.2 & 9.1 & 6.8 \\
\hline & $\pm \mathrm{m}$ & 0.8 & 1.7 & 4.1 & 4.8 \\
\hline $\begin{array}{l}\text { Changes to the initial point, } \\
\%\end{array}$ & - & - & $+78.2^{*}$ & $+138.7^{*}$ & $+79.5 \% *$ \\
\hline \multirow[t]{2}{*}{ Capsaicin + ketorolac } & M & 4.1 & 7.8 & 7.8 & 5.4 \\
\hline & $\pm \mathrm{m}$ & 1.6 & 3.7 & 3.8 & 1.3 \\
\hline $\begin{array}{l}\text { Changes to the initial point, } \\
\%\end{array}$ & - & - & $+89.3^{*}$ & $+89.3^{*}$ & $+31.0^{*}$ \\
\hline \multirow[t]{2}{*}{ Capsazepine } & M & 4.7 & 4.5 & 5.2 & 7.3 \\
\hline & $\pm \mathrm{m}$ & 1.5 & 1.5 & 1.2 & 0.6 \\
\hline $\begin{array}{l}\text { Changes to the initial point, } \\
\%\end{array}$ & - & - & -3.8 & +10.12 & $+54.8^{*}$ \\
\hline \multirow[t]{2}{*}{ Ketorolac + capsazepine } & M & 4.7 & 7.7 & 6.7 & 5.2 \\
\hline & $\pm \mathrm{m}$ & 1.0 & 1.0 & 1.5 & 0.6 \\
\hline $\begin{array}{l}\text { Changes to the initial point, } \\
\%\end{array}$ & - & - & $+63.2^{*}$ & $+41.4^{*}$ & +11.0 \\
\hline \multirow[t]{2}{*}{ Capsazepine + ketorolac } & M & 5.1 & 7.7 & 6.7 & 6.8 \\
\hline & $\pm \mathrm{m}$ & 1.0 & 1.3 & 1.4 & 1.1 \\
\hline $\begin{array}{l}\text { Changes to the initial point, } \\
\%\end{array}$ & - & - & $+51.3^{*}$ & $+30.5^{*}$ & +22.7 \\
\hline
\end{tabular}

both with capsaicin and capsazepine neutralises its effects (Table 4). The obtained data allow concluding that capsaicin and capsazepine almost have no influence on the amplitude and frequency of the portal vein contractions caused by ketorolac, which shows its potential to effect on TRPV1. For further experimental verification, we performed in vivo experiments on a model of thermal nociceptive stimulation - Tail-flick (characterising the spinal level of nociception). The largest number of TRPV1 are in spinal neurons (Scotland et al., 2004). It is commonly known that under the influence of capsaicin on a body after TRPV1 excitation, the refractory period follows during which the nocireceptors are irresponsive not only to the action of the agonists but also to the action of other active stimuli (chemicals, temperature, etc.) (Suh and Oh, 2005). Therefore, while estimating the effect of capsaicin on the antinociceptive activity of these substances, we first of all examined the period up to $30 \mathrm{~min}$ after its introduction, i.e., the period of algogenic activity of the analyser. A latency decrease was marked in the group of animals which were treated with capsaicin. The introduction of capsazepine showed no significant changes during the first $15 \mathrm{~min}$ in the magnitude of latency in comparison with the initial one. On the 60th min the latency increased to $+54.85 \%$. This can be explained as caused by the blockade of capsazepine for the receptor.

In our study on the Tail-flick model, it was revealed that introduction of ketorolac caused a significant analgetic effect, the peak of which we observed 30 min after its introduction (Table 5). The studies showed that the introduction of ketorolac first to the animals followed by capsaicin caused a significant increase of latency, the peak of which was achieved 30 min $(+138.7 \%)$ after the beginning of the study. The introduction of capsaicin before ketorolac also caused a significant increase 


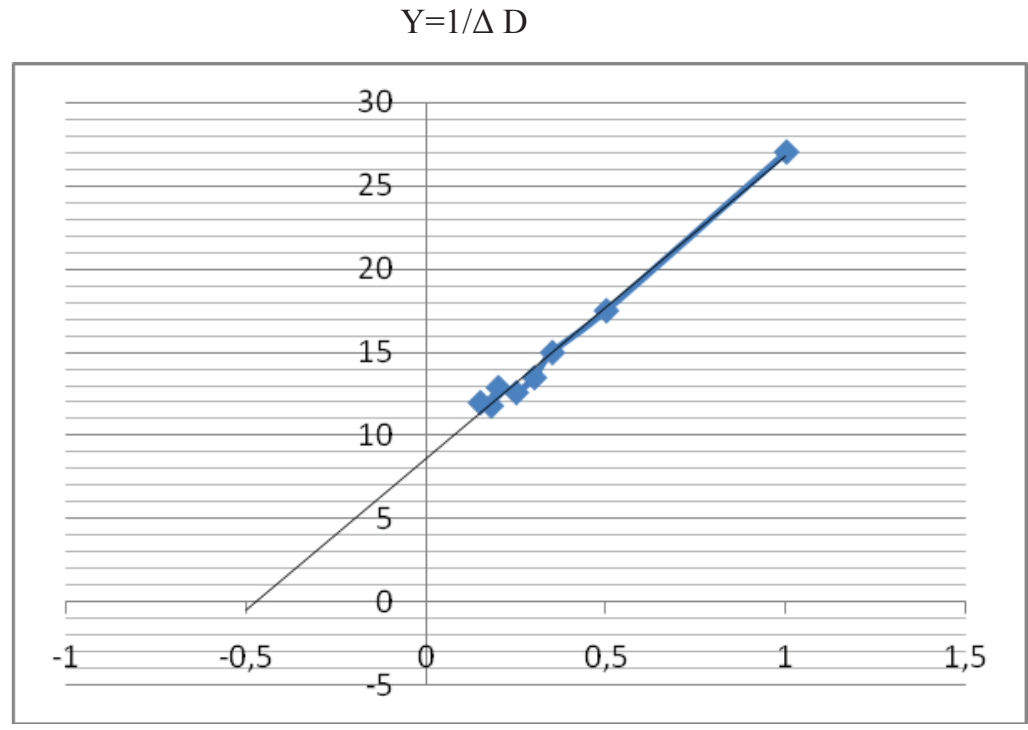

$$
\mathrm{X}=\left(1 / \mathrm{C}_{\mathrm{A}}\right) * 10^{4}, \mathrm{~L} / \mathrm{mol}
$$

Fig. 3 Spectrofluorimetric definition of ketorolac complex $(A)$ with Tyr-Ser $(B)$ in ethanol. (Concentration of ketorolac is constant $\left.C_{A}=2,5 \cdot 10^{-5}, \mathrm{~mol} / \mathrm{L}, \lambda=300 \mathrm{~nm}, D \lambda_{A}=0.220\right)$. The dependence of $1 / \Delta D-1 / \mathrm{S}_{B} \cdot \mathrm{Kr}=0,53 \cdot 10^{-4} \mathrm{~L} / \mathrm{mol}\left(K_{\mathrm{kor}}=-0,98\right)$

of the effect though at a low level (89.3\%). The complex administration of capsazepine and ketorolac (as shown in the chart with capsazepine + ketorolac and in the chart with ketorolac + capsazepine) did not cause any fundamental changes as compared with ketorolac alone. We can come to a conclusion about the influence of capsaicin on the antinociceptive effects of ketorolac and the factual absence of modulation of analgetic effects of capsazepine.

\section{References}

[1] Akerman S, Kaube H, Goadsby PJ. Anandamide acts as a vasodilator of dural blood vessels in vivo by activating TRPV1 receptors. Br J Pharmacol. 2004;142(8): 1354-1360.

[2] Aronoff DM, Oates JA, Boutaud O. New insights into the mechanism of action of acetaminophen: Its clinical pharmacologic characteristics reflect its inhibition of the two prostaglandin H2 synthases. Clin Pharmacol Ther. 2006; 79(1):9-19.

[3] Díaz-Reval MI, Ventura-Martínez R, Dŭciga-Campos M, et al. Evidence for a central mechanism of action of S-(+)ketoprofen. Eur J Pharmacol. 2004;483(2-3):241-248.

[4] Gibbons JD, Chakraborti S. Nonparametric statistical inference. Boca Raton: CRC Press; 2011.

[5] Hugestztt ED, Junsson BAG, Ermund A. Conversion of Acetaminophen to the Bioactive N-Acylphenolamine AM404 via Fatty Acid Amide Hydrolase-dependent Arachidonic Acid Conjugation in the Nervous System. J Biol Chem. 2005; 280(36): 31405-31412.

[6] Komlos E, Porsresr J. Morfin - prostigmin synergismus. Az Acta Phisiologica Acad Scient Hungaricae. 1950;1: 77-83.

\section{Conclusion}

The potentiality for a complex formation of ketorolac with dipeptide Tyr-Ser, the ability to neutralise the effects of capsaicin and capsazepine during the experiment on the portal vein, as well as modulation of its effect in the experiment in vivo allow assuming that TRPV1 can activate a pharmacological influence of ketorolac on the body.

[7] Metzler DE, Metzler CM. Biochemistry: The chemical reactions of living cells, San Diego, CA [etc.]: Harcourt/Academic Press; 2001.

[8] Masubuchi Y, Ose A, Horie T. Diclofenac-induced inactivation of CYP3A4 and its stimulation by quinidine. Drug Metab and Disp. 2002;30(10):1143-1187.

[9] Mroszczak EJ, Lee FW, Combs D. Ketorolac tromethamine absorption, distribution, metabolism, excretion, and pharmacokinetics in animals and humans. Drug Metab Dispos. 1987;15:618-626.

[10] Pegram BL. The portal vein is a model for resistance vassels. In: Pegram BL. Vascular Neuroeffector Mechanisms. New-York: Raven Press; 1980.

[11] Premkumar LS, Sikand P. TRPV1: A Target for next generation Analgesics. Curr Neuropharmacol. 2008;6(2):151163.

[12] Roberts LJ, Marrow JD. Analgesic-antipyretic and antiinflammatory agents and drugs employed in the treatment of Gout. In: Hardman J.G., Limbird L.E. Goodman \& 
Gilman's The Pharmacological Basis of Therapeutics 10th Edition. McGraw Hill; 2001.

[13] Scotland RS, Chauhan S, Davis C et al. Vanilloid receptor TRPV1, sensory C-fibers, and vascular autoregulation. Circ Res. 2004;95:1027-1034.

[14] Suh YG, Oh U. Activation and activators of TRPV1 and their pharmaceutical implication. Curr Pharm Des. 2005(11):2687-2698.

[15] The engineer's ultimate guide to wavelet analysis. The wavelet tutorial (http://users.rowan.edu/ polikar/wave-

\section{Contact name:}

Oleg Yadlovski, PhD

SI “Institute of pharmacology and toxicology NAMS of Ukraine”, Kiev, Ukraine

yadlovskyi@online.ua lets/wttutorial.html). Revised January 2011. Accessed September 15, 2011.

[16] Urban L, Dray A. Capsazepine, a novel capsaicin antagonist, selectively antagonises the effects of capsaicin in the mouse spinal cord in vitro. Neurosci Lett. 1991;134:9-11.

[17] Varrassi G., Marinangel F, Agrò F et al. A double-blinded evaluation of propacetamol versus ketorolac in combination with patient-controlled analgesia morphine: analgesic efficacy and tolerability after gynecologic surgery. Anesth Analg. 1999;88:611. 